\title{
Ranking and causes of inefficiency of container seaports in South-Eastern Europe
}

\author{
Spyros Niavis • Theodore Tsekeris
}

Received: 14 October 2011 / Accepted: 23 May 2012 /Published online: 13 June 2012

(C) The Author(s) 2012. This article is published with open access at SpringerLink.com

\begin{abstract}
Purpose This paper aims at benchmarking, measuring and identifying major determinants of the technical efficiency of container seaports in the region of South-Eastern Europe, including the Italian ports which directly affect competition in the wider region of East Mediterranean Sea.

Methods The study employs both non-parametric (standard and super-efficiency DEA) models and bootstrapped parametric techniques to provide a more holistic approach and useful insight into the given problem.

Results and conclusions The results indicate the relatively low (below $50 \%$ ) average total technical efficiency of the container ports in the study region, which can be attributed to both the lack of managerial skills and scale effects. The findings can help to determine sources of port inefficiency by geographical location and size and adopt best practices to improve the operational performance of container ports.
\end{abstract}

Keywords Container ports · Efficiency management · Data envelopment analysis $\cdot$ Benchmarking $\cdot$ South-Eastern Europe

\section{Introduction}

The past 15 years have been a period of great and rapid changes in the political regime and economic status of the

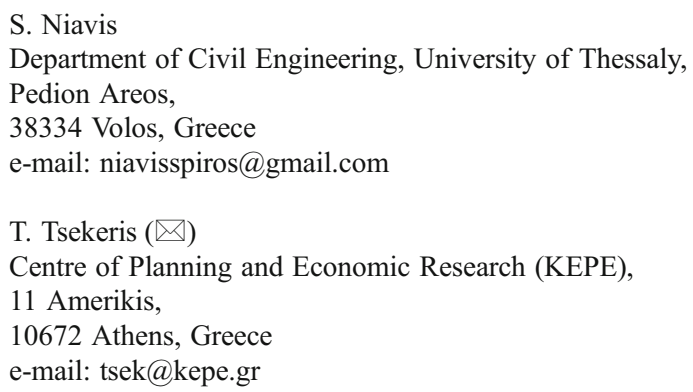

countries of South-Eastern Europe (SEE). Amongst others, several changes have been observed in the transport sector, which concern both the amount of and the way cargo is shipped. These changes have explicitly affected the operational structure of seaports and shipping industries. After a long period of underdevelopment, the port industry in the region nowadays constitutes a sector with favourable prospects for boosting economic growth [31]. Ports are considered as critical nodes of international trade networks and economic co-operation, bearing the largest share of the total imported and exported cargo volumes.

These exceptional prospects have resulted in the growth of competition between ports in the region. There are two facts which mainly contribute to competitive conditions: the continuous increase of the total cargo transferred and the spread of transhipment container flows. Many port authorities have realized the opportunities arisen from container transport operations, because of the resulting high added value, and they have gradually carried out investment plans to facilitate container transfers. These investments increased the volume of container flows in many ports and brought about remarkable changes in the hierarchical position of ports, in terms of the volume of containers handled [40].

The competitive environment in which seaports operate tends to become even more complicated, as the private sector plays an increasingly dominant role in their development [1]. This changing competitive environment has particularly affected the Mediterranean ports. The global enterprises, such as world carriers and terminal operators, show a great interest to control, via the ports, the market of SEE and East Mediterranean region. The container transport network becomes steadily more dispersed across the region, taking into account the different interests and strategies of the main trade partners. Seaports constitute a sub-system in the global logistics chain and some of them may gradually 
lose their bargaining power vis-à-vis their clients, whose choices mostly rely on decreasing generalized transport cost. Operational (or technical) efficiency and adaptability to the globalized supply chain networks and the new competition environment are key components for the success and survival of each port $[22,31,35]$.

The present study primarily aims at the operational performance benchmarking of the container ports of SEE, including those of Italy, since they are directly influencing port competition in the wider region. In the first stage, both the technical efficiency and scale economies are analyzed through the use of Data Envelopment Analysis (DEA) methods. In the next (second) stage, a bootstrapped truncated regression methodology is adopted to determine the impact which various factors, beyond the control of port authorities, have on the efficiency and, subsequently, the competitive position of ports. In this way, the proposed approach uniquely addresses potential problems of small-sample bias typically met in standard parametric estimates and consistently supports management decisions of port operators regarding the internal and external operational environment and their competitive strategy. The study is organized as follows: Section 2 provides a comprehensive review of modeling issues and methodologies related to seaport efficiency analysis and Section 3 presents the proposed methodology. Section 4 describes the model variables and Section 5 reports the results of the DEA models and explains the role of key determinants of port efficiency. Section 6 summarizes and concludes, including some insights for the further development of the regional port system.

\section{Literature review}

The measurement and evaluation of seaport operational efficiency and competitiveness is of important academic interest, as reflects the increasing amount of international literature in this field from various perspectives. A group of studies has examined the competitiveness of seaports by estimating the attractiveness they have on their users. In this category, the factors which influence the attractivity of ports and choices of carriers are investigated by employing such techniques as multinomial logistic regression $[28,46,51,55]$, analytic hierarchy process (AHP) [44,54], factor analysis [42], principal component analysis [50] and extended survey analyses [32].

On the other hand, a significant amount of research has concentrated on the effectiveness and efficiency of seaports as basic components of their competitiveness. These studies make use of such techniques as multiple regression [48], AHP [27] and productivity measures [2,23,45]. Besides, another group of studies incorporates techniques from the analysis of questionnaires to measure the ports' business performance $[33,36]$.

Moreover, great emphasis has been given to the measurement of the technical (operational) efficiency of seaports. This measurement is carried out by applying techniques for the analysis of production frontiers; they are distinguished into non-parametric methodologies, mostly the DEA, and parametric ones, typically the stochastic frontier analysis (SFA). Both DEA and SFA can be regarded as the most widely used approaches for the performance measurement of seaports, as they encompass the concept of benchmarking [14]. Hence, they constitute a powerful management tool for each seaport authority, since they help to identify and interpret its weaknesses and strengths in relation to its direct competitors.

These two methodologies are based on different assumptions concerning their application. DEA focuses on the comparison of the technical efficiency of a number of Decision Making Units (DMUs). It involves the solution of a series of linear programming problems, in which both the inputs and outputs of the production process are employed to calculate the relative efficiency of each DMU. The methodology was first suggested by Farrell [18] and it was then extended by Charnes et al. [7] and Banker et al. [3]. The two basic DEA models refer to the DEA-CCR model, which assumes constant returns to scale (CRS), and the DEA-BCC model, which assumes variable returns to scale (VRS).

Roll and Hayuth [41] first adopted the DEA-CCR model to evaluate the efficiency of ports, using a hypothetical sample of 20 DMUs. Several studies have afterwards been carried out by adopting either the CCR model [49] or the BCC model [29], or by using both of the two models $[4,5,15,24,39,56,58]$.

Furthermore, there are numerous studies of port efficiency which have suggested various theoretical extensions of the two basic DEA models. More specifically, Tongzon [49] adopted the Super-Efficiency DEA model to allow the reranking of the efficient ports. Park and De [38] adopted the four-stage DEA model, which is used in order to evaluate the productivity, profitability, marketability and, finally, the overall efficiency of each port. Lee et al. [25] employed the recursive DEA (or RDEA) model, which constitutes a multistage DEA model. Many researchers have implemented a window-based DEA, which examines the technical efficiency of ports in concrete intervals of time [13,16,30]. Additionally, Hung et al. [21] used the bootstrapped DEA method in order to reduce the statistical noise (mainly, due to sampling bias) of the basic DEA models. Other studies which include the DEA as a tool for benchmarking ports are critically reviewed by Panayides et al. [37].

SFA methodology is based on specific production functions and, hence, it incorporates the basic principles of 
production economic theory. It adapts econometric techniques for the efficiency estimation to determine a production frontier. The specific methodology attributes the deviation from the frontier to the loss of efficiency in the production process and to the randomness or statistical noise [15]. This methodology was first implemented for the measurement of port efficiency by Liu [26], using data from 28 British ports. Quite a few other studies employed SFA to estimate through production frontiers the technical efficiency of ports [11,12,17,34,50,57]. Amongst them, Notteboom et al. [34] and Yan et al. [57] used Bayesian theory to produce more statistically consistent estimates. Coto-Millan et al. [10] and Barros [6] adopted the SFA for the econometric estimation of the cost frontiers of seaports. Trujillo and Tovar [52] and Gonzalez and Trujillo [20] focused on the estimation of efficiency using SFA with a translog distance function.

The two categories of methodologies display specific strengths and weaknesses. The basic strength of DEA is its simplicity, as it constitutes a non-parametric analysis, which is independent from assumptions on production functional form and error distribution. However, this simplicity comes with the cost of generating results which lack statistical properties. Additionally, SFA estimations encompass statistical properties, as SFA adapts econometric techniques for the efficiency estimation. The main disadvantage of SFA methodology arises from the fact that, as an econometric approach, it comes up with strong a priori assumptions about the production technology of seaports, since the true production technology is unknown.

Taking into account the strengths and limitations of the two methodologies, the choice between them relies on the specific characteristics of the problem at hand. In the present study, the DEA methodology will be adapted in order to measure the efficiency of SEE ports. The choice of DEA is primarily based on the small number of ports which constitute the sample. The solution of econometric models with such a small number of observations may turn out to be inefficient and unstable, because of the problem of limited degrees of freedom which typically arises.

In addition to estimating the container port efficiency, the present study will investigate the main factors which influence it. These factors lay beyond the control of port authorities and can indirectly affect the performance of each port. The sole study employing DEA to measure port efficiency taking into account these specific factors is that of Turner et al. [53], which focuses on the productivity of North American ports. In comparison to that study, the present one employs several extensions to both the measurement of efficiency scores (using the Super-Efficiency DEA model) and the identification of their main determinants (using a bootstrapped truncated regression method) in order to yield more efficient and accurate results. The proposed methodology and formulation of the models are described in Section 3.

\section{Methodology for two-stage efficiency analysis}

This section first describes the formulation of the DEA models as implemented here for the measurement of container port efficiency. Let us assume that there are $n$ DMUs to be analyzed, each of which uses $m$ inputs to produce $s$ outputs. Also assume that $x_{i j}>0$ is the amount of input $i$ used by the DMU $j$ and $y_{r j}>0$ is the amount of output $r$ produced by that DMU. In this study, it is hypothesized that the objective is to produce a given output using a minimum of inputs; hence, an input-oriented model is considered as more suitable than an output-oriented model. The DMUs are port authorities, which may have complete control over the outputs, provided that the carriers are the agents selling container storage space and transporting containers. The input-oriented DEA-CCR model can be described as:

$$
\begin{array}{lll}
\theta^{*}=\min \theta & \\
\text { s.t. } & \sum_{j=1}^{n} x_{i j} \lambda_{j} \leq \theta x_{i o} & i=1,2, \ldots, m \\
& \sum_{j=1}^{n} y_{r j} \lambda_{j} \geq y_{r o} & r=1,2, \ldots, s \\
& \lambda_{j} \geq 0 & \mathrm{j}=1,2, \ldots, n
\end{array}
$$

where

$y_{r o}$, the $r$ th output and $i$ th input for a DMU $o$ under

$x_{i o} \quad$ evaluation

$\lambda_{j} \quad$ the decision variables which represent the weights DMU $j$ would place on DMU $o$ in constructing its efficient reference set, and

$\theta^{*} \quad$ the relative technical efficiency of DMU $o$.

The variable $\theta^{*}$ can receive either the unit value, which renders a unit relatively efficient, or a value lower than unity $(<1)$, which renders the unit relatively inefficient. The DEABCC model results from adding the convexity condition $\sum_{j=1}^{n} \lambda_{j}=1$ to the constraints of the DEA-CCR model (1).

In addition to the DEA-CCR and DEA-BCC models, the Super-Efficiency DEA model is employed for the performance measurement of container ports. The efficiency scores from the latter model are obtained through eliminating the data of the DMU that is being evaluated from the solution set. The scores of the inefficient DMUs remain the same with those resulted from the two basic DEA models. The difference is that the efficient DMUs are differentiated among each other by presenting distinct scores above unity. The Super-Efficiency DEA model can be regarded here as more preferable than the basic DEA models. This is because it can disentangle the most efficient ports (those with both CRS and VRS efficiency scores equal to one); hence, its results can be used in an easier and more plausible way (they 
are only lower-limit constrained to zero) in the econometric analysis of determinants that follows in the second stage (see Section 5). When a DMU performs a score above unity, then this unit is called Super-Efficient. The basic DEA-CCR (or CRS) Super-Efficiency model can be described as follows:

$$
\begin{array}{lll}
\min \theta^{\text {sup } e r} & & \\
\text { s.t. } & \sum_{\substack{j=1 \\
j \neq o}}^{n} x_{i j} \lambda_{j} \leq \theta^{\text {sup } e r} x_{i o} & i=1,2, \ldots, m \\
& \sum_{\substack{j=1 \\
j \neq o}}^{n} y_{r j} \lambda_{j} \geq y_{r o} & r=1,2, \ldots, s \\
& \lambda_{j} \geq 0 & \\
& &
\end{array}
$$

The DEA-BCC (or VRS) Super-Efficient model results from adding the constraint $\sum_{j=1}^{n}{ }_{j \neq o} \lambda_{j}=1$ to the constraints of model (2) [9].

Following the DEA-based performance measurement of each container port (first stage), the present paper aims at assessing the effect of several determinants (explanatory variables) of technical efficiency (second stage). The use of the Super-Efficiency DEA scores facilitates the identification of the role of its determinants (environmental factors) at the latter stage. This is because it allows disentangling their influence on the most efficient ports which may take values beyond unity, as in the case of SEE ports (see Section 5), and it circumvents the problem of imposing upper-bound (unity) constraints, compared to the case of adopting the standard DEA results.

Furthermore, the DEA-CCR Super-Efficiency scores $\theta^{\text {super }}$ are used as the dependent variable at this stage of analysis, since they express the total technical efficiency (both the pure technical efficiency and scale effects) of container ports $j=1, \ldots, n$. By using some regression model, the effect of each determinant $k=1, \ldots, K$ on $\theta^{\text {super }}$ scores is identified. In a generalized form (omitting the constant term), this model can be formulated as follows:

$\theta_{j}^{\text {sup } e r}=\sum_{k=1}^{K} \beta_{k} x_{k j}+\varepsilon_{j}$,

where $\beta_{k}$ denotes the coefficient corresponding to the $k$ th determinant and $\varepsilon_{j}$ is an independent and identically distributed random error term. Since the efficiency scores $\theta^{\text {super }}$ are constrained to the minimum value of zero, the Tobit regression technique [47] is typically implemented to solve Eq. (3), in order to address the censorship bias which may result from the use of Ordinary Least-Squares (OLS) method. The Tobit model represents the potential (expected) value of the dependent variable $\theta^{\text {super }}$ as a latent variable, $\widehat{\theta}^{\text {sup } e r}$, which can only be partially observed within the feasible range of efficiency scores $(\geq 0)$, as follows:

$$
\begin{gathered}
\widehat{\theta}_{j}^{\text {sup } e r}=\sum_{k=1}^{K} \beta_{k} x_{k j}+\varepsilon_{j} \\
\theta_{j}^{\text {sup } e r}= \begin{cases}0, & \text { if } \widehat{\theta}_{j}^{\text {sup } e r} \leq 0 \\
\widehat{\theta}_{j}^{\text {sup } e r}, & \text { if } \widehat{\theta}_{j}^{\text {sup } e r}>0\end{cases}
\end{gathered}
$$

The Tobit Regression was adapted in the study of Turner et al. [53] in order to estimate the effect of several factors on the efficiency of the North American ports. However, model (4) relies on (censoring) assumptions which are not consistent with the true data generation process, yielding inaccurate estimates of the standard error of parameters. This is because efficiency scores constitute point estimates without statistical distribution, as it is required by Tobit (or other parametric regression) techniques, and they may be correlated with explanatory variables. In order to improve the accuracy of results, Simar and Wilson [43] suggested the use of truncated regression with parametric bootstrapping, which can produce more consistent and efficient model coefficients. Specifically, the distribution of the error term $\varepsilon_{j} \sim N\left(0, \sigma_{\varepsilon}^{2}\right)$ is assumed to be uniformly truncated with zero mean (before truncation) and unknown variance $\sigma_{\varepsilon}^{2}$, so that ensure the negative-value constraint of the dependent variable. Both the Tobit and truncated regression models are solved here by using the maximum likelihood method and iterative parametric bootstrap simulation techniques.

\section{Description of the model variables}

The present study includes 30 seaports in the wider region of SEE, with total annual container volume over 20000 TEUs. These container ports encompass Odessa (Ukraine), Constantza (Romania), Varna and Burgas (Bulgaria), Ambarli, Haydarpasa, Diliskelesi, Gemlik, Tekirdag and Izmir (Turkey), Piraeus, Volos and Salonica (Greece), Durres (Albania), Bar (Montenegro), Ploce and Rijeka (Croatia) and Koper (Slovenia). The Italian ports (Trieste, Venice, Ravenna, Savona, Genoa, La Spezia, Leghorn, Naples, Salerno, Taranto, Gioia Tauro and Palermo) are also included in the sample because they are directly competitive to the container ports of SEE. Figure 1 illustrates the geographical position of all the container ports included in the study.

Based on the availability of data and on other (production function) model specifications employed in similar studies in the literature [37], the current DEA models include three (3) inputs: number of berths, length of quays and number of cranes used by each port for container handling, and one (1) output: total throughput, in terms of TEUs, for the year 




Fig. 1 Geographical illustration of the container ports in South-Eastern Europe

2008. The data were collected from the Containerisation International Yearbook (CIY) [8] and, in a few cases, from the website of port authorities. The chosen input and output variables can be plausibly assumed that adequately represent the production function of container seaports.

The determinants of efficiency refer to factors related to the direct and indirect operational environment of ports. The direct operational environment of ports is described with two variables. The first variable refers to the size of ports and is measured by their total area $\left(\mathrm{km}^{2}\right)$, to capture the size effects on port efficiency. The second variable refers to their regulatory status and is described within a dummy variable. It takes the value 0 if the operation of container handling is under the control of a public or local authority, and the value 1 if a global (private-sector) terminal operator is involved in the container handling operation. The indirect environment of port operation is described with 3 variables. The first variable refers to the distance of each port from Suez, which denotes the relative importance of geographical position in the region. The second variable refers to the economic status of the territory in which the port is located, as expressed by the measure of per-capita Gross Domestic Product (GDP). Finally, the third variable of the indirect environment is the population of the area at the hinterland of each port. Table 1 presents the descriptive statistics of the input and output variables as well as of the environmental variables of the DEA models.

\section{Results of two-stage efficiency analysis}

This section presents and analyzes the results of the twostage efficiency analysis of SEE ports. In the first stage, the results of the DEA models used for the performance measurement of container ports under study are analyzed. In the second stage, the results of the regression of explanatory variables on the port efficiency scores are presented. Table 2 indicates the CRS, VRS and CRS Super-Efficiency scores and some descriptive statistics. The CRS efficiency scores measure the overall technical efficiency, encompassing the pure technical and scale efficiencies, whereas the VRS efficiency scores measure the pure technical efficiency only, which reflects the managerial skills of port operators.

The ratio of the overall technical efficiency (CRS) score to pure technical efficiency (VRS) score yields the measure of scale efficiency. Gioia Tauro and Izmir are found to be completely efficient, namely, both their CRS and VRS efficiency scores are equal to unity. Nonetheless, based on the CRS Super-Efficiency scores, the port of Gioia Tauro is the most efficient one (1.803), compared to the port of Izmir (1.376). In addition, Venice, Bar, Ploce and Durres are found to have VRS efficiency score equal to unity, which implies that they operate optimally in terms of pure technical efficiency (or they optimally manage their existing resources), but the deficit in scale efficiency $(<1)$ results in a loss of total technical efficiency (CRS efficiency score $<1$ ). 
Table 1 Descriptive statistics of the inputs and outputs and explanatory variables

\begin{tabular}{|c|c|c|c|c|c|c|c|c|}
\hline & \multicolumn{3}{|l|}{ Inputs } & \multirow{2}{*}{$\begin{array}{l}\text { Output } \\
\text { Volume } \\
\text { TEUs }\end{array}$} & \multicolumn{4}{|c|}{ Explanatory variables } \\
\hline & Berths & $\begin{array}{l}\text { Length } \\
(\mathrm{m})\end{array}$ & Cranes & & $\begin{array}{l}\text { Area } \\
\left(\mathrm{km}^{2}\right)\end{array}$ & $\begin{array}{l}\text { Population } \\
\text { (in } 000 \mathrm{~s} \text { ) }\end{array}$ & $\begin{array}{l}\text { GDP per capita } \\
(€ 000 \mathrm{~s})\end{array}$ & $\begin{array}{l}\text { Distance from Suez } \\
(\mathrm{km})\end{array}$ \\
\hline Mean & 6.33 & 1549.8 & 11.0 & 586078.6 & 508.6 & 1385.2 & 0.150 & 518.1 \\
\hline Median & 4 & 1074 & 7 & 335972 & 235 & 206.6 & 0.028 & 503.3 \\
\hline Std. Dev. & 5.66 & 1527.8 & 9.7 & 769517.3 & 821.3 & 2871.6 & 0.261 & 126.1 \\
\hline Min. & 1 & 265 & 1 & 21814 & 38 & 6.5 & .0005 & 303.5 \\
\hline Max. & 25 & 7720 & 35 & 3467772 & 4485.3 & 11372.6 & 0.9777 & 720.5 \\
\hline
\end{tabular}

All the other container ports are found to be relatively inefficient, in terms of both pure technical and scale efficiency. On average, the total technical efficiency of the ports in the whole region can be considered as relatively low (42\%, in terms of the CRS efficiency scores, and $46 \%$, in terms of the CRS Super-Efficiency scores). The average
Table 2 Presentation of the container port efficiency scores (in descending order of CRS Super-Efficiency scores)

\begin{tabular}{|c|c|c|c|c|}
\hline Port & CRS & VRS & Scale efficiency & CRS super -efficiency \\
\hline Gioia Tauro & 1.000 & 1.000 & 1.000 & 1.803 \\
\hline Izmir & 1.000 & 1.000 & 1.000 & 1.376 \\
\hline Taranto & 0.838 & 0.945 & 0.887 & 0.838 \\
\hline Constantza & 0.697 & 0.753 & 0.925 & 0.697 \\
\hline Trieste & 0.688 & 0.955 & 0.720 & 0.688 \\
\hline Venice & 0.676 & 1.000 & 0.676 & 0.676 \\
\hline Odessa & 0.663 & 0.884 & 0.750 & 0.663 \\
\hline Naples & 0.663 & 0.825 & 0.803 & 0.663 \\
\hline La Spezia & 0.597 & 0.660 & 0.905 & 0.597 \\
\hline Koper & 0.561 & 0.887 & 0.633 & 0.561 \\
\hline Ambarli & 0.534 & 0.542 & 0.985 & 0.534 \\
\hline Salerno & 0.419 & 0.645 & 0.650 & 0.419 \\
\hline Gemlik & 0.399 & 0.631 & 0.632 & 0.399 \\
\hline Haydarpasa & 0.392 & 0.575 & 0.681 & 0.392 \\
\hline Salonica & 0.379 & 0.719 & 0.527 & 0.379 \\
\hline Genoa & 0.340 & 0.351 & 0.968 & 0.340 \\
\hline Ravenna & 0.340 & 0.512 & 0.664 & 0.340 \\
\hline Leghorn & 0.318 & 0.369 & 0.863 & 0.318 \\
\hline Bar & 0.277 & 1.000 & 0.277 & 0.277 \\
\hline Rijeka & 0.268 & 0.545 & 0.491 & 0.268 \\
\hline Varna & 0.263 & 0.658 & 0.399 & 0.263 \\
\hline Ploce & 0.223 & 1.000 & 0.223 & 0.223 \\
\hline Durres & 0.208 & 1.000 & 0.208 & 0.208 \\
\hline Diliskelesi & 0.201 & 0.461 & 0.436 & 0.201 \\
\hline Savona & 0.191 & 0.325 & 0.588 & 0.191 \\
\hline Piraeus & 0.183 & 0.229 & 0.800 & 0.183 \\
\hline Burgas & 0.078 & 0.343 & 0.228 & 0.078 \\
\hline Volos & 0.069 & 0.500 & 0.138 & 0.069 \\
\hline Tekirdag & 0.030 & 0.235 & 0.130 & 0.030 \\
\hline Palermo & 0.021 & 0.191 & 0.112 & 0.021 \\
\hline Average & 0.417 & 0.658 & 0.610 & 0.457 \\
\hline Std Dev. & 0.271 & 0.269 & 0.287 & 0.382 \\
\hline
\end{tabular}


DEA-BCC (under VRS) and scale efficiency scores are found to be relatively higher ( $66 \%$ and $61 \%$, respectively) than the average DEA-CCR and CCR Super-Efficiency (under CRS). The above findings indicate that both the lack of managerial skills and scale diseconomies are important sources of inefficiency for the most of the container ports in the study region.

The relative role of pure technical (managerial) inefficiency and scale effects on the total technical efficiency of container ports can be more easily explained through the graphical illustration of the corresponding CRS and VRS scores as data (on the $y$-axis and $\mathrm{x}$-axis, respectively) pairs on a two-dimensional graph (see Fig. 2). This graph is divided into four regions, according to a line vertical to the $\mathrm{x}$-axis which denotes the average VRS score $(0.658)$ and a line representing the average scale efficiency $(0.61)$, that is, CRS Efficiency $=0.61 *$ VRS Efficiency. The ports located at the upper-right part of the graph have both high pure technical (VRS) and scale efficiency scores, which implies that they can well exploit their facilities and serve a large amount of containers (TEUs). The ports located at the lower-right part of the graph have high pure technical efficiency but relatively low (compared to the average value) scale efficiency. Although these ports well manage their facilities, they are subject to scale effects as they are not able to adequately accommodate the volume of containers arrived at them. The ports located at the upper-left part of the graph have relatively low pure technical efficiency but relatively high scale efficiency. These ports accommodate a large number of containers with limited performance, as they do not efficiently manage their resources. The ports located at the lower-left part of the graph have both relatively low pure technical efficiency and scale efficiency. Namely, these ports serve low TEU traffic with inefficient use of their facilities. Thus, they need to improve their competitive position by attracting more containers as well as better managing their resources.

Figure 3 illustrates the variations of VRS and CRS SuperEfficiency scores of container ports by geographical location. The effect of the location of ports is investigated in terms of three geographical groups: Italy, Turkey and Balkans (Greece, Albania, Montenegro, Croatia, Slovenia, Bulgaria and Romania), including Odessa (Ukraine). On average, the ports of Italy are found to have higher total technical efficiency (0.575) than those of Turkey (0.489) and Balkans (0.323). Nonetheless, the ports of Balkans have, on average, higher pure technical efficiency $(0.710)$ than those of Italy $(0.648)$ and Turkey (0.574). These findings stress the important positive role of scale economies on the efficiency of Italian container ports and on their competitiveness in the sea trade market of the region. As it can be also observed in Fig. 2, the ports of Palermo and Savona are the only Italian ports which are located at the lower part of the graph. On the other side, as far as the Balkan area is concerned, only the ports of Piraeus (Greece) and Constantza (Romania) as well as Odessa (Ukraine) are located at the upper part of the graph, namely, they have scale efficiency above the average level in the region. Except of the port of Rijeka (Croatia), the Greek (Piraeus, Volos and Salonica) and Bulgarian (Varna and Burgas) ports are the only Balkan ports located at the left part of the graph, which implies that they adversely influence the average pure technical efficiency of the other Balkan ports.

Furthermore, some hypotheses can be tested in relation to the efficiency rankings of the container ports in the region. The two hypotheses stated here are: (i) Large container ports, in terms of the TEUs serviced, are more efficient than small container ports, and (ii) Italian container ports are systematically more efficient than the other container ports in the SEE region. The Mann-Whitney $U$-test, which tests for the existence of systematic differences between the efficiency scores, is adopted. This test is considered as suitable for the non-parametric statistical analysis of DEA results [19], because the efficiency scores do not typically follow a standard normal distribution. The CRS SuperEfficiency scores are chosen for the analysis, because they capture the total technical efficiency and adequately discriminate the efficient DMUs. Regarding the first hypothesis, the whole sample of ports is divided into two subsamples, based on the TEUs. The statistic value
Fig. 2 Graphical illustration of container port efficiency

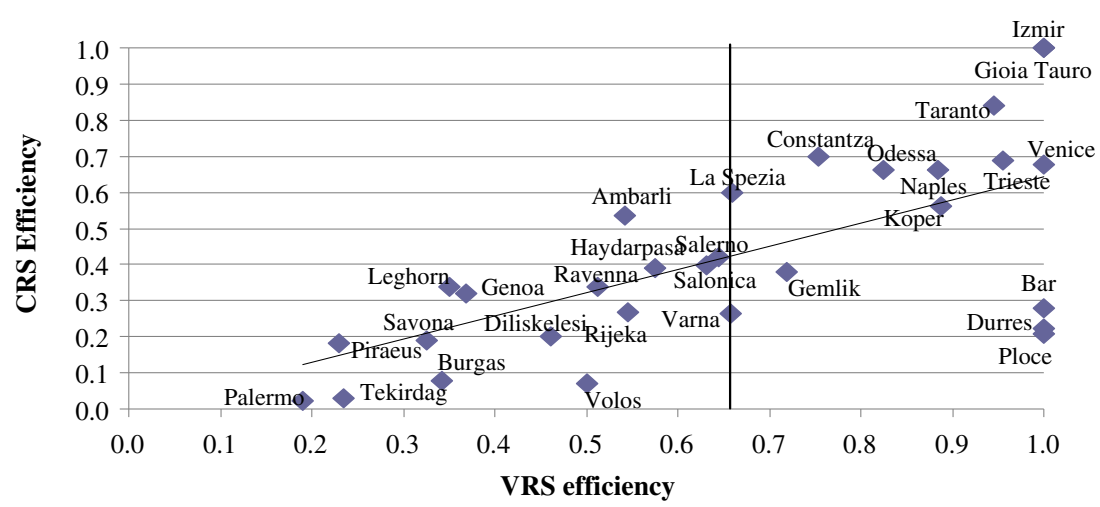




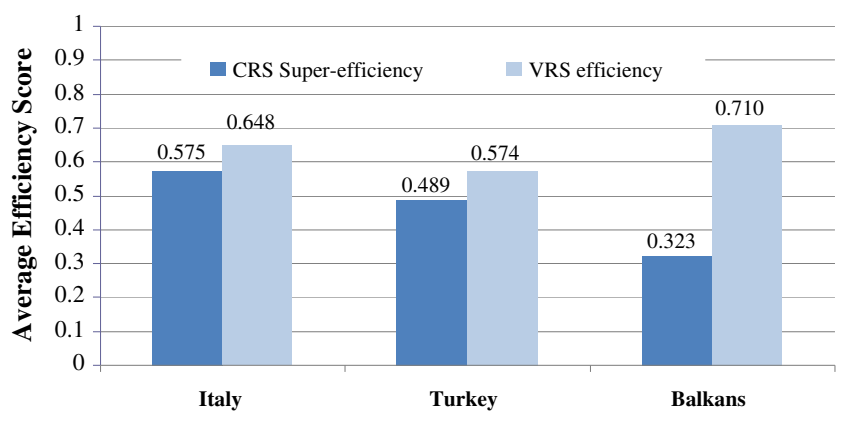

Fig. 3 Average efficiency of container ports by geographical location

$z=-3.463$ with Prob $>|z|=0.0005$ demonstrates, as expected, that the larger ports are significantly more efficient because of economies of scale. In other words, the size of operations and technical efficiency of ports are systematically positively related to each other. Regarding the second hypothesis, the subsample of the twelve Italian container ports is compared to a subsample comprising the twelve most efficient SEE container ports. The statistic value $z=-0.462$ with $\operatorname{Prob}>|z|=$ 0.6442 indicates that there is no systematic difference in the efficiency between the Italian and the other SEE container ports. This outcome may be explained by the different natures and characteristics pertaining to the ports within each subsample and the fact that the competitive advantage of Italian ports, in terms of their increased scale efficiency, is somewhat compensated by the relatively higher pure technical efficiency of the other SEE ports.

Table 3 indicates the results of the econometric models used to determine the influence of each explanatory variable on container port efficiency. The two models, i.e., Tobit and truncated regression, yield coefficients of the same sign (with the exception of population variable whose influence is found to be statistically insignificant). However, the latter model is found to perform better, as reflects the statistical significance of parameter estimates. More specifically, based on the results of bootstrapped truncated regression, the port area variable is found to have a statistically significant positive effect on port efficiency. Namely, larger ports tend to operate more efficiently than smaller ports. This finding is consistent with that of other studies in the literature [50,53], which have shown a clear positive relationship between the size and efficiency of ports.

The effect of the control of container handling operations by a global terminal operator is also found to be positive and statistically significant. This result denotes that the privatization of port operations, when it is combined with the involvement of a globalized partner, is associated with improved port efficiency. Other studies which have also demonstrated the positive impact of privatization on the port efficiency are those of Cullinane et al. [11], Estache et al. [17], Cullinane and Song [12] and Tongzon and Heng [50].

Moreover, the variable of the distance from Suez has a statistically significant negative impact on port efficiency. This result is plausible, since the ports with preferential placement near the international sea trade corridors passing from Suez are rendered more attractive for the world carriers in their effort to save time, than the more distant ports. These ports usually show an increased specialization in container handling and, hence, they tend to manage containers more efficiently. Finally, the impact of per-capita GDP, as well as that of population, on the efficiency of container ports is found to be statistically insignificant.

\section{Conclusions}

Container seaports constitute a key element for increasing trade and economic growth rate of countries in the wider SEE region. The improvement of technical efficiency is critical for facilitating the role of ports as drivers of economic success in the modern competitive environment. By concentrating on the technical efficiency analysis of SEE container seaports, this paper employed a non-parametric (DEA) methodology and a bootstrapped parametric technique to address possible problems of biased estimates due to the small sample size and limited degrees of freedom. In contrast with the existing research in the field, the proposed two-stage procedure can benchmark and disentangle the
Table 3 Results of the econometric analysis of determinants of port efficiency

\begin{tabular}{lccccc}
\hline Variable & \multicolumn{2}{l}{ Tobit regression } & & \multicolumn{2}{l}{ Bootstrap truncated regression } \\
\cline { 2 - 3 } & Coefficient & Prob $>|\mathrm{z}|$ & & Coefficient & Prob > $|\mathrm{z}|$ \\
\hline Port area (km² in logarithm) & 0.146 & 0.127 & & 0.211 & 0.040 \\
Population (in 000s in logarithm) & 0.030 & 0.969 & & -0.043 & 0.622 \\
Per-capita GDP (in 000 Euros) & 0.607 & 0.133 & & 0.751 & 0.473 \\
Distance from Suez (in km) & -0.001 & 0.087 & & -0.002 & 0.030 \\
Private & 0.257 & 0.129 & & 0.467 & 0.040 \\
Sigma & 0.273 & 0.048 & & 0.349 & 0.000 \\
\hline
\end{tabular}


most efficient ports and, then, it can consistently allow the identification of key determinants of port efficiency. This approach can be considered as integrated: it helps the container port operators to realize both their weaknesses in relation to direct competitors and how the internal and external operational environment affects the efficiency of their production process.

The results signify the existence of inefficiency pertaining to the management of container ports in the region, since the total technical efficiency is found to be below $50 \%$ on average. The Balkan ports generally show the lowest levels of technical efficiency. This relatively limited operating performance of SEE container ports indicates the need for appropriate capital investments for the efficient processing of TEUs. In particular, those ports whose efficiency is not favored by such factors as size, geographical position and socio-economic conditions of the region wherein they are located, must adopt suitable reform strategies to promptly improve their production process and competitive position. These strategies should aim at modernizing/upgrading the port facilities and mechanical equipment, enhancing their accessibility/connection with hinterland areas and the training of employees, adopting best practices and implementing training and know-how transfer from other port authorities.

New funding sources for these strategies can be obtained through effective regulatory reforms and private concession schemes with global terminal operators for selected terminals. The penetration of private-sector companies in the management of container port facilities is growing worldwide and existing evidence has demonstrated the positive role of such schemes in the efficiency and development of relevant port operations. The ongoing privatization trends are expected to boost the overall efficiency of container ports, provided that their operations will be fully internationalized and will actively participate in world-wide logistics networks.

Open Access This article is distributed under the terms of the Creative Commons Attribution License which permits any use, distribution and reproduction in any medium, provided the original author(s) and source are credited.

\section{References}

1. Acosta M, Coronado D, Del Mar Cerban M (2011) Bunkering competition and competitiveness at the ports of the Gibraltar Strait. J Transp Geogr 19(4):911-916

2. Ashar A (1997) Counting the moves. Port Dev Int 13:25-29

3. Banker RD, Charnes A, Cooper W (1984) Some models for estimating technical and scale inefficiencies in Data Envelopment Analysis. Manag Sci 30(9):1078-1092
4. Barros CP (2003) The measurement of efficiency of Portuguese sea port authorities with DEA. Int J Transp Econ 30(3):335-354

5. Barros CP, Athanassiou M (2004) Efficiency in European seaports with DEA: evidence from Greece and Portugal. Marit Econ Logist 6(2):122-140

6. Barros CP (2005) Decomposing growth in Portuguese seaports: a frontier cost approach. Marit Econ Logist 7:297-315

7. Charnes A, Cooper WW, Rhodes E (1978) Measuring the efficiency of decision making units. Eur J Oper Res 2(6):429-444

8. Containerisation International Yearbook (CIY) (2010) EMAP Business Publications, London, U.K.

9. Cooper WW, Seiford LM, Zhu J (2004) Data envelopment analysis: history, models and interpretations. In: Cooper WW, Seiford LM, Zhu J (eds) Handbook on data envelopment analysis, chapter 1. Kluwer Academic Publishers, Boston, pp 1-39

10. Coto-Millan P, Banso-Pino J, Rodriguez-Alvarez A (2000) Economic efficiency in Spanish ports: some empirical evidence. Marit Policy Manag 27(2):169-174

11. Cullinane KPB, Song DW, Gray R (2002) A stochastic frontier model of the efficiency of major container terminals in Asia: assessing the influence of administrative and ownership structures. Transp Res A 36(8):743-762

12. Cullinane KPB, Song DW (2003) A stochastic frontier model of the productive efficiency of Korean container terminals. Appl Econ 35(3):251-267

13. Cullinane KPB, Song D-W, Ji P, Wang T (2004) An application of DEA Windows analysis to container port production efficiency. Rev Netw Econ 3(2):186-208

14. Cullinane K, Song DW (2006) Estimating the relative efficiency of European container ports: a stochastic frontier analysis. In: Cullinane K, Talley WK (eds) Port economics. Elsevier, Oxford, pp 85-115

15. Cullinane K, Wang T-F, Song D-W, Ji P (2006) The technical efficiency of container ports: comparing data envelopment analysis and stochastic frontier analysis. Transp Res A 40(4):354-374

16. Eraqi Al AS, Mustafa A, Khader AT, Barros CP (2008) Efficiency of Middle-Eastern and East African seaports: application of DEA using window analysis. Eur J Sci Res 23(4):597-612

17. Estache A, González M, Trujillo L (2002) Efficiency gains from port reform and the potential for yardstick competition: lessons from Mexico. World Dev 30(4):545-560

18. Farrell MJ (1957) The measurement of productive efficiency. J R Stat Soc Ser A 120:253-281

19. Golany B, Roll Y (1989) An application procedure for DEA. OMEGA Int J Manag Sci 17(3):237-250

20. Gonzalez MM, Trujillo L (2008) Reforms and infrastructure efficiency in Spain's container ports. Transp Res A 42(1):243-257

21. Hung SW, Lu WM, Wang TP (2010) Benchmarking the operating efficiency of Asia container ports. Eur J Oper Res 203(3):706-713

22. Jacobs W, Hall PV (2007) What conditions supply chain strategies of ports? the case of Dubai. GeoJournal 68:327-342

23. Kim M, Sachish A (1986) The structure of production, technical change and productivity in a port. J Ind Econ 35(2):209-223

24. Koster MBM, Balk BM, van WTI Nus (2009) On using DEA for benchmarking container terminals. Int J Oper Prod Manag 29 (11): 1140-1155

25. Lee HS, Chou MT, Kuo SG (2005) Evaluating port efficiency in Asia Pacific region with recursive data envelopment analysis. J East Asia Soc Transp Stud 6:544-559

26. Liu Z (1995) The comparative performance of public and private enterprises: the case of British ports. J Transp Econ Policy 29 (3):263-274

27. Mahalik DK, Kumar S, Patel G (2010) Efficiency measurement using DEA and AHP: a case study on Indian ports. IUP J Supply Chain Manag 7(1-2):34-48

28. Malchow M, Kanafani A (2004) A disaggregate analysis of port selection. Transp Res E 40(4):317-337 
29. Martinez-Budria E, Diaz-Armas R, Navarro-Ibanez M, RaveloMesa T (1999) A study of the efficiency of Spanish port authorities using data envelopment analysis. Int J Transp Econ 26(2):237-253

30. Min H, Park B-I (2005) Evaluating the inter-temporal efficiency trends of international container terminals using data envelopment analysis. Int J Integr Supply Manag 1(3):258-277

31. Niavis S, Polyzos S (2009) 'The port system of SE Europe: an analysis of variables influencing the ports' container throughput', Proceedings of the 2nd Panhellenic Conference on Planning and Regional Development, Thessaly University Press, Volos, Greece

32. Ng KYA (2006) Assessing the attractiveness of ports in the North European container transhipment market: an agenda for future research in port competition. Marit Econ Logist 8(3):234-250

33. Ng AKY, Tongzon JL (2010) The transportation sector of India's economy: dry ports as catalysts for regional development. Eurasian Geogr Econ 51(5):669-682

34. Notteboom T, Coeck C, van den Broech J (2000) Measuring and explaining the relative efficiency of container terminals by means of Bayesian stochastic frontier models. Int J Marit Econ 2(2):83-106

35. Notteboom TE, Winkelmans W (2001) Structural changes in the logistics: how will port authorities face the challenge? Marit Policy Manag 28(1):71-89

36. Pallis AA, Vitsounis TK (2010) Key interactions and drivers towards port users satisfaction. In: Hall PV, McCalla R, Slack B, Comtois $\mathrm{C}$ (eds) Integrating seaports and trade corridors. Ashgate, Aldershot, pp 119-136

37. Panayides PM, Maxoulis CN, Wang T-F, Ng KYA (2009) A critical analysis of DEA applications to seaport economic efficiency measurement. Transp Rev 29(2):183-206

38. Park R, De P (2004) An alternative approach to efficiency measurement of seaports. Marit Econ Logist 6(1):53-69

39. Poitras G, Tongzon J, Li H (1996) 'Measuring port efficiency: an application of data envelopment analysis' Working paper, National University of Singapore, Singapore

40. Polyzos S, Niavis S (2008) 'The perspective of the combination of rail and maritime transportation in Greece', Proceedings of the 8th National Congress of ERSA Greek Section "Urban Development in Greece and European Union”, Athens, Greece

41. Roll Y, Hayuth Y (1993) Port performance comparison applying data envelopment analysis. Marit Policy Manag 20(2):153-161

42. Sanchez RJ, Ng AKY, Garcia-Alonso L (2011) Port selection factors and attractiveness: the service suppliers' perspective. Transp J 50(2):141-161
43. Simar L, Wilson PW (2007) Estimation and inference in two stage, semi-parametric models of productive efficiency. J Econ 136 (1):31-64

44. Song DW, Yeo K-T (2004) A competitive analysis of Chinese container ports using the analytic hierarchy process. Marit Econ Logist 6:34-52

45. Tabernacle JB (1995) A study of the changes in performance of quayside container cranes. Marit Policy Manag 22(2):115-124

46. Tiwari P, Itoh H, Doi M (2003) Shippers' port and carrier selection behaviour in China: a discrete choice analysis. Marit Econ Logist 5:23-39

47. Tobin J (1958) Estimation of relationships for limited dependent variables. Econometrica 26(1):24-36

48. Tongzon J (1995) Determinants of port performance and efficiency. Transp Res A 29(3):245-252

49. Tongzon J (2001) Efficiency measurement of selected Australian and other international ports using data envelopment analysis. Transp Res A 35(2):113-128

50. Tongzon J, Heng W (2005) Port privatization, efficiency and competitiveness: some empirical evidence from container ports (terminals). Transp Res A 39(5):405-424

51. Tongzon J, Sawant L (2007) Port choice in a competitive environment: from the shipping lines' perspective. Appl Econ 39(4):477492

52. Trujillo L, Tovar B (2007) The European port industry: an analysis of its economic efficiency. Marit Econ Logist 9(2):148-171

53. Turner H, Windle R, Dresner M (2004) North American container port productivity: 1984-1997. Transp Res E 40 (4):339-356

54. Ugboma C, Ugboma O, Ogwude IC (2006) An Analytic Hierarchy Process (AHP) approach to port selection decisions-empirical evidence from Nigerian ports. Marit Econ Logist 8:251-266

55. Veldman SM, Bückmann EH (2003) A model on container port competition: an application for the West European container hubports. Marit Econ Logist 5:3-22

56. Wang T-F, Cullinane K (2006) The efficiency of European container terminals and implications for supply chain management. Marit Econ Logist 8(1):82-99

57. Yan J, Sun X, Liu JJ (2009) Assessing container operator efficiency with heterogeneous and time-varying production frontiers. Transp Res B 43(1):172-185

58. Wu Y-CJ, Goh M (2010) Container port efficiency in emerging and more advanced markets. Transp Res E 47(1):1030-1042 